\title{
Socio-demographic determinants and effect of structured personal diabetes care: a 19-year follow-up of the randomized controlled study diabetes Care in General Practice (DCGP)
}

Andreas Heltberg ${ }^{1,2,3^{*}}$, Volkert Siersma ${ }^{2}$, John Sahl Andersen ${ }^{1}$, Christina Ellervik ${ }^{3,4,5}$, Henrik Brønnum-Hansen ${ }^{6}$, Jakob Kragstrup ${ }^{1}$ and Niels de Fine Olivarius ${ }^{2}$

\begin{abstract}
Background: We investigated how four aspects of socio-demography influence the effectiveness of an intervention with structured personal diabetes care on long-term outcomes.

Methods: The Diabetes Care in General Practice (DCGP) study is a cluster-randomized trial involving a populationbased sample of 1381 patients with newly diagnosed type 2-diabetes mellitus. We investigated how education, employment, cohabitation status and residence influenced the effectiveness of 6 years of intervention with structured personal diabetes care, resembling present day recommendations. Outcomes were incidence of any diabetes-related endpoint and death during 19 years after diagnosis, and cardiovascular risk factors, behaviour, attitudes and process-of-care variables 6 years after diagnosis.
\end{abstract}

Results: Structured personal care reduced the risk of any diabetes-related endpoint and the effect of the intervention was modified by geographical area (interaction $p=0.034)$ with HR of 0.71 (95\%Cl: $0.60-0.85$ ) and of 1. 07 (95\%Cl: 0.77-1.48), for patients in urban and rural areas, respectively. Otherwise, there was no effect modification of education, employment and civil status on the intervention for the final endpoints. There were no noticeable socio-demographic differences in the effect of the intervention on cardiovascular risk factors, behaviour, attitudes, and process-of-care.

Conclusion: Structured personal care reduced the aggregate outcome of any diabetes-related endpoint and independent of socio-demographic factors similar effect on cardiovascular risk factors, behaviour, attitudes and process of care, but the intervention did not change the existing inequity in mortality and morbidity. Residence modified the uptake of the intervention with patients living in urban areas having more to gain of the intervention than rural patients, further investigations is warranted.

Trial registration: ClinicalTrials.gov registration no. NCT01074762 (February 24, 2010).

Keywords: Type 2 diabetes mellitus, Social inequalities, Intervention, Clinical outcomes

\footnotetext{
* Correspondence: anhe@sund.ku.dk

'Section of General Practice, Institute of Public Health, Faculty of Health

Sciences, University of Copenhagen, Øster Farimagsgade 5, Copenhagen,

Denmark

${ }^{2}$ The Research Unit for General Practice, Department of Public Health,

University of Copenhagen, Copenhagen, Denmark

Full list of author information is available at the end of the article
} 


\section{Background}

Epidemiological studies have repeatedly shown increased occurrence of type 2 diabetes mellitus (T2DM) among people with low socioeconomic status [1,2] and living in rural areas [3]. Primarily due to improved diabetes care, mortality of T2DM patients has decreased substantially in recent decades [4], although this trend has been less favourable among those with low socio-economic status (SES) [5-10]. A recent Scandinavian study showed increased mortality among people of low SES, but could not show any systematic differences in mortality between patients living in rural and urban areas [8].

Social inequality in mortality and morbidity of patients with T2DM can only be partially explained by differences in the increased incidence of other comorbid disease $[1,11]$. SES has been reported to influence metabolic control [12], pharmacological treatment [13] and ability to change lifestyle according to the recommendations $[14,15]$. Inequality in access to and utilization of health care $[16,17]$ could influence the course of T2DM $[18,19]$.

Though SES and place of living influence care and prognosis of T2DM $[8,10,11,20]$, there is only limited evidence as to whether the effectiveness of diabetes interventions differs with regard to SES and residence. Recent reports suggest that interventions with intensive diabetes care diminish the socio-economic differences in intermediate outcomes [13, 21], but we do not know whether this effect also is seen on long-term outcomes. One may hypothesize, that an intervention with structured personal care may succeed to reduce the difference between socio-demographic groups [13], as the effectiveness of this intervention in two post hoc analyses have been reported to be especially pronounced in women [22] and in patients with severe mental illness [23].

Our aim in the present study is to describe how sociodemographic status and residence influences the effectiveness of an intervention with structured personal care in newly diagnosed patients with T2DM regarding allcause mortality and any diabetes-related endpoint during 19 years of follow-up.

\section{Methods}

\section{Patients}

The Diabetes Care in General Practice (DCGP) study was a pragmatic, open, multicentre, cluster-randomized controlled trial (ClinicalTrials.gov registration no. NCT01074762) [18]. The purpose of the trial was to test whether structured personal care, compared to routine care, for patients newly diagnosed with T2DM, reduced the incidence of seven pre-defined outcomes, including all-cause mortality and any diabetes-related outcome $[18,24]$. In 1988, a random sample of two thirds of Danish general practices, excluding singlehanded practices with a doctor aged $\geq 60$ years, received an invitation to participate in the study. Of 1902 general practitioners (GPs), 474 (25.4\%) volunteered. In 1989-1992, all practices included all patients aged 40 years or over with newly diagnosed diabetes based on strict criteria [18]. All practices were randomized to either six years of structured personal care or routine care in the period 1989-1995 and all patients had a follow up examination 6 years after diagnosis [24]. The inclusion criteria were met by 1590 patients, of which 209 patients were excluded according to predefined criteria, so that the number of study participants was 1381 (Fig. 1). Among these patients, 1369 (99.1\%) were of western European descent and, based on onset of insulin treatment, most were considered to have T2DM (97.5\%). The Ethics Committee of Copenhagen and Frederiksberg (V.100.869/87) approved the study and all patients gave informed consent.

\section{Intervention}

The Danish healthcare system is mainly tax-financed and based on the egalitarian principle of equal healthcare access for all equal healthcare needs, clinic visits are free of charge and expenditures for prescribed drugs are for the most part reimbursed. In Denmark the GP usually provides diagnosis and routine care for T2DM and function as gatekeeper for specialist care.

In the intervention arm follow-up every 3 months and annual screening for diabetes complications were supported by sending out a questionnaire to GPs one month before the next expected consultation. Goal-setting for blood glucose, blood pressure, lipids and weight was individualized [24], and GPs were introduced to possible solutions to therapeutic problems through six annual half-day seminars, descriptive annual reports on individual patients as well as folders and leaflets for doctors and patients, resembling present day recommendations for diabetes care $[25,26]$. None of the intervention procedures were explicitly based on social differentials. Patients were never approached by the study centre. GPs in the routine care group were free to choose any treatment and change it over time [24] and they were not contacted after patient inclusion had stopped until the intervention was terminated and the 6-year examination was initiated in September 1995.

\section{Assessments}

At the time of diagnosis and at the 6-year follow up examination measures of patients' health and social status were collected in questionnaires to GPs, eye doctors and patients. Upon inclusion, patients gave information about socio-demographic variables in questionnaires: highest attained education level (basic school education only or higher education level); in labour market, out of labour market or retired; and whether patients lived 


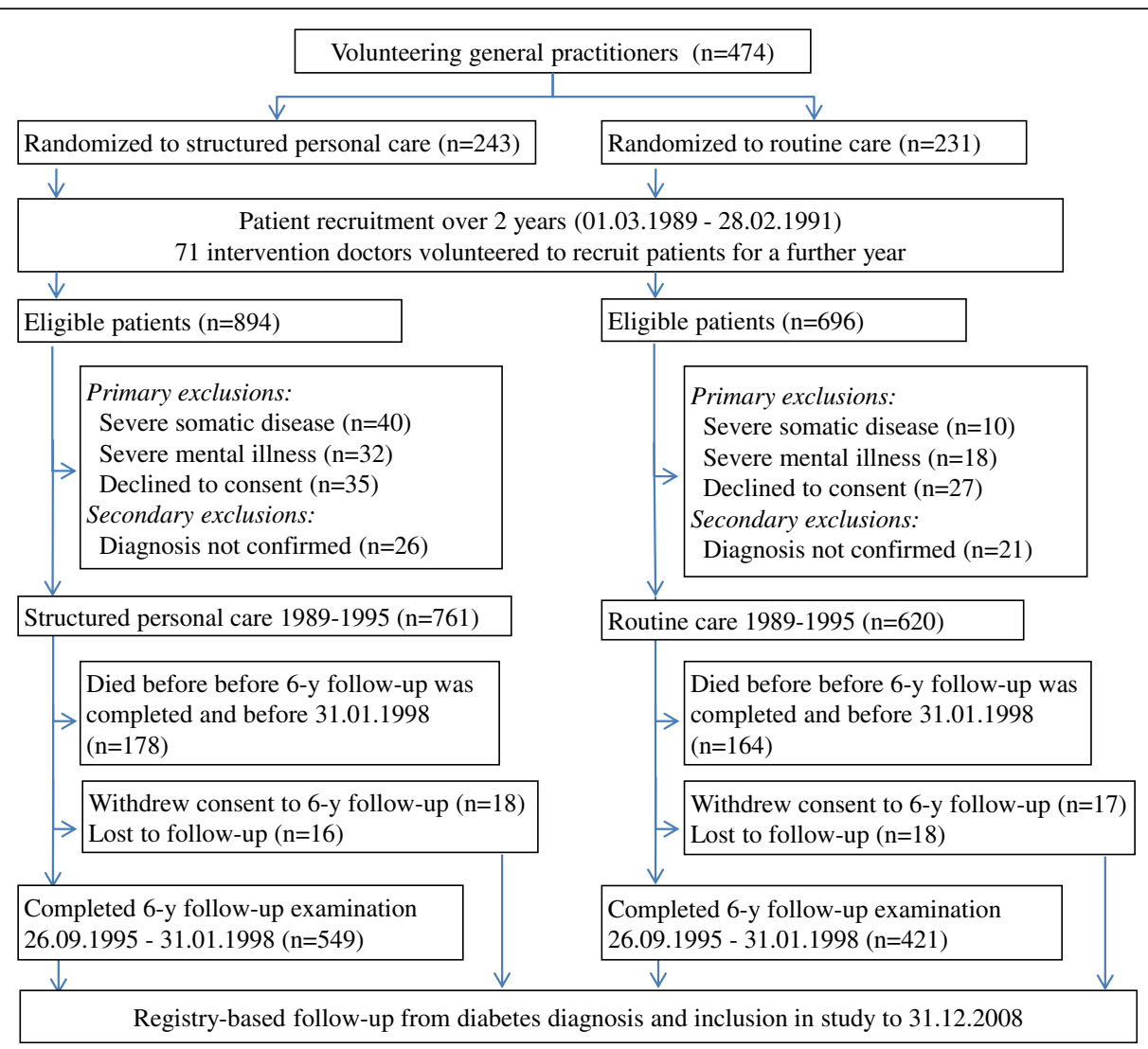

Fig. 1 Patient flow diagram from inclusion until 19-year register based follow-up

alone or were cohabiting/married. Information on smoking habits and leisure-time physical activity was also collected. Information on place of living was recorded as rural or urban from area code and population density in accordance with Statistics Denmark [27].

\section{Clinical and registry based follow-up}

The clinical 6-year follow-up examination included measurement of body weight, blood pressure, urinary albumin, haemoglobin A1c (HbA1c), total cholesterol, fasting triglycerides, and serum creatinine. Patients and doctors were asked to fill in questionnaires including questions on health behaviour (smoking, physical activity), attitudes towards disease (altered habits, diet and home monitoring of blood glucose), patient's motivation for best possible control according to the GP, process-of-care (number of consultations, number of diabetes-related consultations and whether patients had been treated at a diabetes clinic) and if they received pharmacological treatment (cholesterollowering, glucose-lowering and antihypertensive drugs).

During 19 years (mean follow-up time) after diabetes diagnosis patients were followed up in the national registers. Vital and emigration status of all patients were certified through the Danish Civil Registration System [28]. Everyone living in Denmark is registered with a permanent and unique personal identification number allowing linkage between study populations and all national registers. Data on mortality, diagnoses and surgical procedures were from The Danish Register of Causes of Death (DCD) [29] and The Danish National Patient Register (DNPR), which includes information on almost all hospital contacts in Denmark [30]. The outcomes used in the registry-based follow up were all-cause mortality and any diabetes-related endpoint.

(e.g. stroke, myocardial infarction and renal failure, full list see (Additional file 1)), previously defined [18] and also used in the UK Prospective Diabetes Study [31].

\section{Statistical analysis}

Differences in the incidence of death and any diabetesrelated endpoint between randomization and sociodemographic groups were analysed univariably with log-rank tests and multivariably in Cox regressions models. In the latter, $95 \% \mathrm{CIs}$ and $p$ values were determined using a sandwich estimator for the variance to account for clustering of patients within practices [30]. Absolute risks were calculated as the number of participants experiencing the corresponding outcome divided by person years of risk. Two multivariable models are presented, one adjusted for age at diagnosis, sex and 
clustering, the other with additional adjustment for the following variables at diagnosis: BMI, hypertension, HbA1c, total cholesterol, urinary albumin, physical activity, smoking, known cardiovascular disease (see Table 1), and prescription of glucose- and/or lipid-lowering and/or antihypertensive drugs.

For behavioural, clinical, biochemical and process-ofcare variables at the 6-year examination we used multivariable generalized linear regression models (ordinary linear regression for continuous variables, logistic regression for binary variables and negative binomial regression for count variables) and presented the effects of structured care vs. routine care, stratified on sociodemographic groups adjusted for age, sex, and diabetes duration. Effect modification was assessed by a test for the interaction between randomization and SES groups in the corresponding model. Clustering with GPs was accounted for by the use of generalized estimating equations. Due to the multiple comparisons the level of statistical significance at $5 \%$ is not interpreted rigorously. We performed a log rank test for all-cause mortality and any diabetes-related endpoint comparing the four groups defined by educational background and the intervention. We used the statistical program SAS v9.4 (SAS Institute, Cary, NC, USA).

\section{Results}

The indirect randomization was successful except that relatively more routine care patients were living in rural areas (Table 1). Overall, a low level of education was associated with higher all-cause mortality (Fig. 2) and any diabetes-related endpoint (Fig. 3) showing significant difference between the 4 groups in respectively all causemortality and any diabetes related endpoint (log-rank

Table 1 Patient characteristics at diabetes diagnosis according to treatment arm

\begin{tabular}{|c|c|c|c|c|}
\hline & $\begin{array}{l}\text { No. of respondents } \\
\text { Routine/ } \\
\text { Structured care }\end{array}$ & $\begin{array}{l}\text { Routine } \\
\text { care }\end{array}$ & $\begin{array}{l}\text { Structured } \\
\text { care }\end{array}$ & $p$-value \\
\hline \multicolumn{5}{|l|}{ Socioeconomic } \\
\hline Age, years & $620 / 761$ & $65.2(73.4 ; 56.2)$ & $65.5(73.7 ; 55.6)$ & 0.59 \\
\hline Male gender & $620 / 761$ & $329(53.1)$ & $404(53.1)$ & 0.99 \\
\hline Living alone & $606 / 743$ & $198(32.7)$ & $236(37.6)$ & 0.72 \\
\hline Rural residence & $596 / 728$ & $161(27.0)$ & $153(21.0)$ & 0.011 \\
\hline Basic school education only & $588 / 723$ & $459(78.1)$ & $574(79.4)$ & 0.56 \\
\hline Employment status & $605 / 744$ & & & 0.51 \\
\hline In labor market & & $157(26.0)$ & $208(28.0)$ & \\
\hline Out of labor market ${ }^{a}$ & & $181(29.9)$ & $203(27.3)$ & \\
\hline Retired & & $267(44.1)$ & $333(44.8)$ & \\
\hline \multicolumn{5}{|l|}{ Medical history } \\
\hline Cardiovascular disease $^{\mathrm{b}}$ & $603 / 743$ & $191(31.7)$ & $223(30.0)$ & 0.51 \\
\hline \multicolumn{5}{|l|}{ Clinical } \\
\hline Body mass index, $\mathrm{kg} / \mathrm{m}^{2}$ & $619 / 753$ & $28.7(32.2 ; 26.0)$ & $29.4(33.0 ; 26.2)$ & 0.21 \\
\hline Hypertension $^{c}$ & $620 / 761$ & $458(73.9)$ & $568(74.6)$ & 0.75 \\
\hline \multicolumn{5}{|l|}{ Biochemical } \\
\hline Fasting plasma glucose, mmol/L & $620 / 761$ & $13.8(10.7 ; 17.1)$ & $13.6(10.7 ; 16.9)$ & 0.44 \\
\hline $\mathrm{HbA}_{1 c} \%^{\mathrm{d}}$ & $512 / 624$ & $10.2(8.7 ; 11.9)$ & $10.2(8.6 ; 11.7)$ & 0.75 \\
\hline Total cholesterol, mmol/L & $620 / 740$ & $6.2(5.5 ; 7.2)$ & $6.2(5.3 ; 7.1)$ & 0.16 \\
\hline Fasting triglycerides, $\mathrm{mmol} / \mathrm{L}$ & $610 / 736$ & $2.0(1.4 ; 3.0)$ & $2.0(1.4 ; 2.9)$ & 0.62 \\
\hline Serum creatinine, $\mu \mathrm{mol} / \mathrm{L}$ & $611 / 740$ & $88(79 ; 100)$ & $90(80 ; 101)$ & 0.41 \\
\hline Urinary micro- or proteinuria ${ }^{e}$ & $595 / 723$ & $254(42.7)$ & $304(42.1)$ & 0.81 \\
\hline \multicolumn{5}{|l|}{ Behavioral } \\
\hline Sedentary (leisure-time) physical activity & $604 / 741$ & $162(26.8)$ & $210(28.3)$ & 0.54 \\
\hline Current smokers & $604 / 742$ & $208(34.4)$ & $264(35.6)$ & 0.66 \\
\hline
\end{tabular}




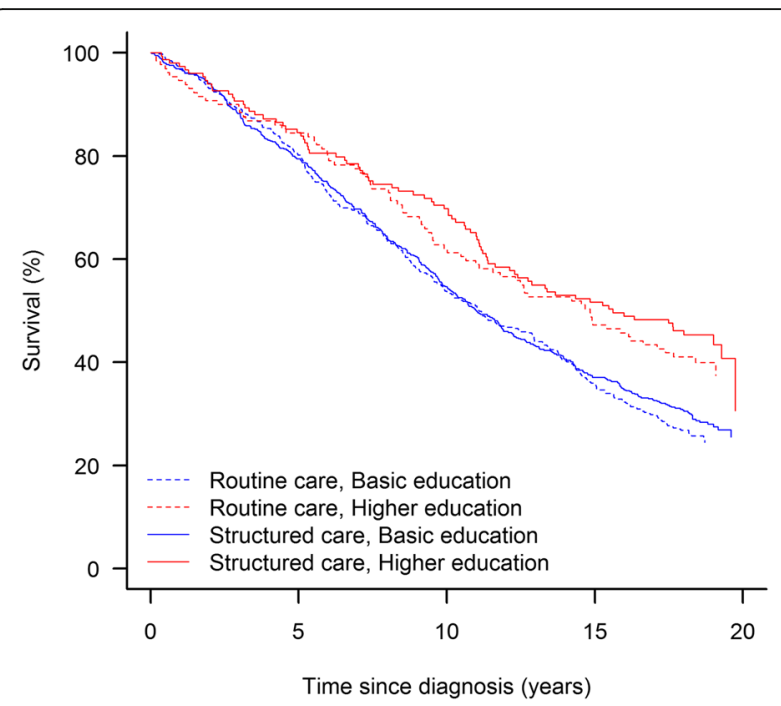

Fig. 2 Kaplan-Meier plot showing the proportion of surviving patients since diabetes diagnosis in patients according to randomization arm and highest attained education level, only basic schooling vs. higher

test, $p<0.0001)$. During 19 years of registry-based follow up structured personal care lowered the risk of any diabetes-related endpoint by $20 \%$ compared with routine care [18], and this effect seems to be most pronounced for patients living in urban areas $(\mathrm{HR}(95 \% \mathrm{CI}) \quad 0.71$; $0.60-0.85)$, patients with only basic level of education $(0.75 ; 0.63-0.89)$, patients outside the labour market $(0.73 ; 0.55-0.97)$ and patients cohabiting $(0.78 ; 0.65-$ 0.93) (Table 2). The effect of the intervention, however, was only statistically significantly different between patients

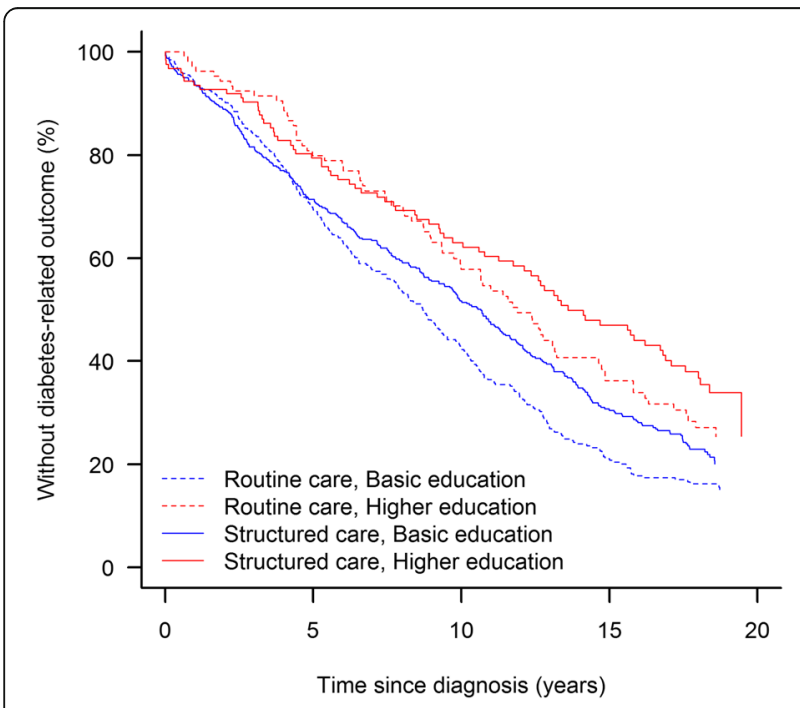

Fig. 3 Kaplan-Meier plot showing the proportion of patients without any diabetes related endpoint since diagnosis according to randomization arm and highest attained education level, only basic schooling vs. higher living in urban and rural areas (interaction $p=0.034$ ). The intervention had no effect on all-cause mortality.

Results describing the role of four different aspects of socio-demography on behavioural, clinical, biochemical and process-of-care variables at the 6-year examination are presented in Additional file 2: Table S1, Additional file 3: Table S2, Additional file 4: Table S3, Additional file 5: Table S4, and summarized with the $p$-values from the test of the corresponding interaction and a description of the association (Table 3). Overall, the effect of the intervention on these variables did not differ according to socio-demography. Only few patients were treated with cholesterol lowering drugs in 1995-96 (1.9\% - 5.8\%), but relatively fewer patients living in rural areas were treated with cholesterol lowering drugs in response to the intervention compared to urban patients. The intervention resulted in an increased number of diabetes-related consultations regardless of socio-demographic group, and patients living alone tended to have relatively more consultations compared to patients cohabiting.

\section{Discussion}

The intervention did not influence all-cause mortality [18], but overall patients receiving structured personal care experienced a $20 \%$ lower risk of any diabetesrelated endpoint compared to patients receiving routine care. This effect was greater among patients living in urban areas compared to rural patients, but otherwise, there was no effect modification of education, employment and civil status on the intervention for the final endpoints. Overall the effect of the intervention on behavioural, biochemical and process-of-care measures was not different between the subgroups of the four aspects of socio-demography.

\section{Comparison with existing literature}

This study reports social inequity in mortality and diabetes-related morbidity, in line with other studies that have investigated the impact of level of education [9], occupation [8] and socio-economic status [7, 8]. The present findings suggest that an intervention with structured personal care does not give rise to more social inequity in use of the health care system, as has been described in other studies [13, 21]. Thus the results do not confirm results from studies of the general population showing that the number of consultations at the GP increases with decreasing socio-economic status [15, 32]. The fact that socio-economic differences in mortality and morbidity persist, despite formally equal access to the public health care system, could be due to different use of specialist care as suggested by others $[17,20]$, but this does not seem to be the case for the intervention in our study. 


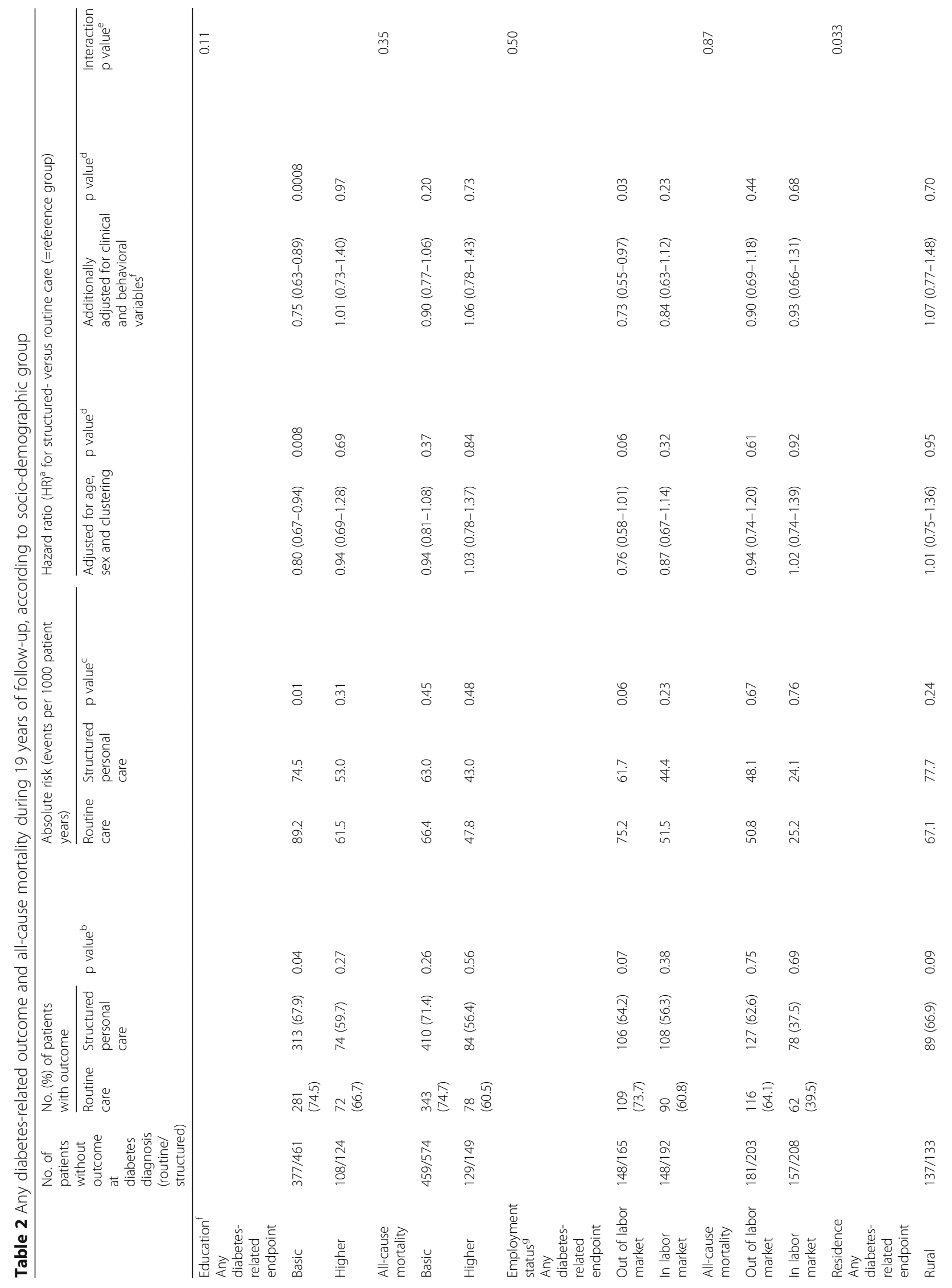




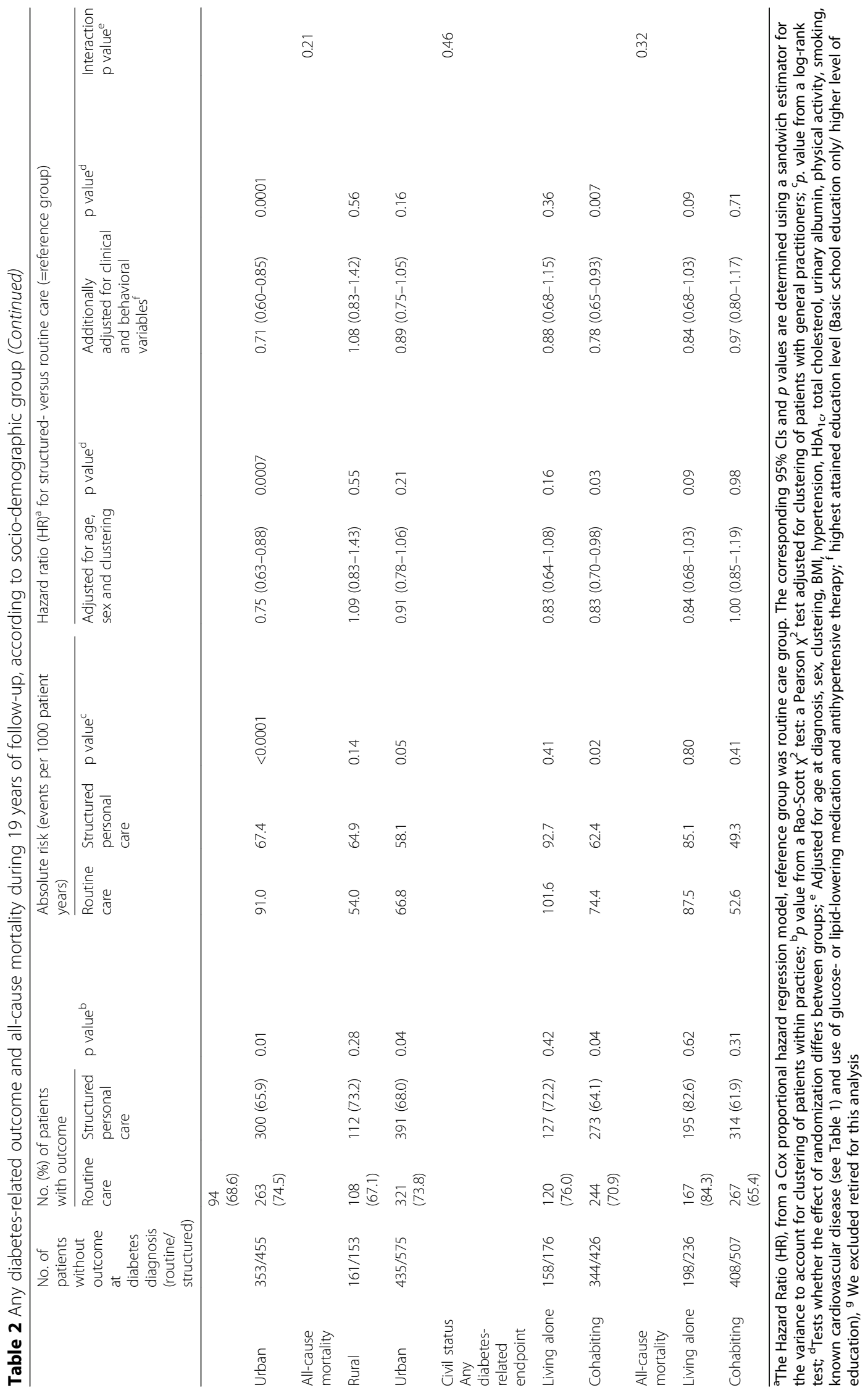


Table 3 The effect of structured personal care on behavioral, clinical, process of care and biochemical variables according to sociodemographic group

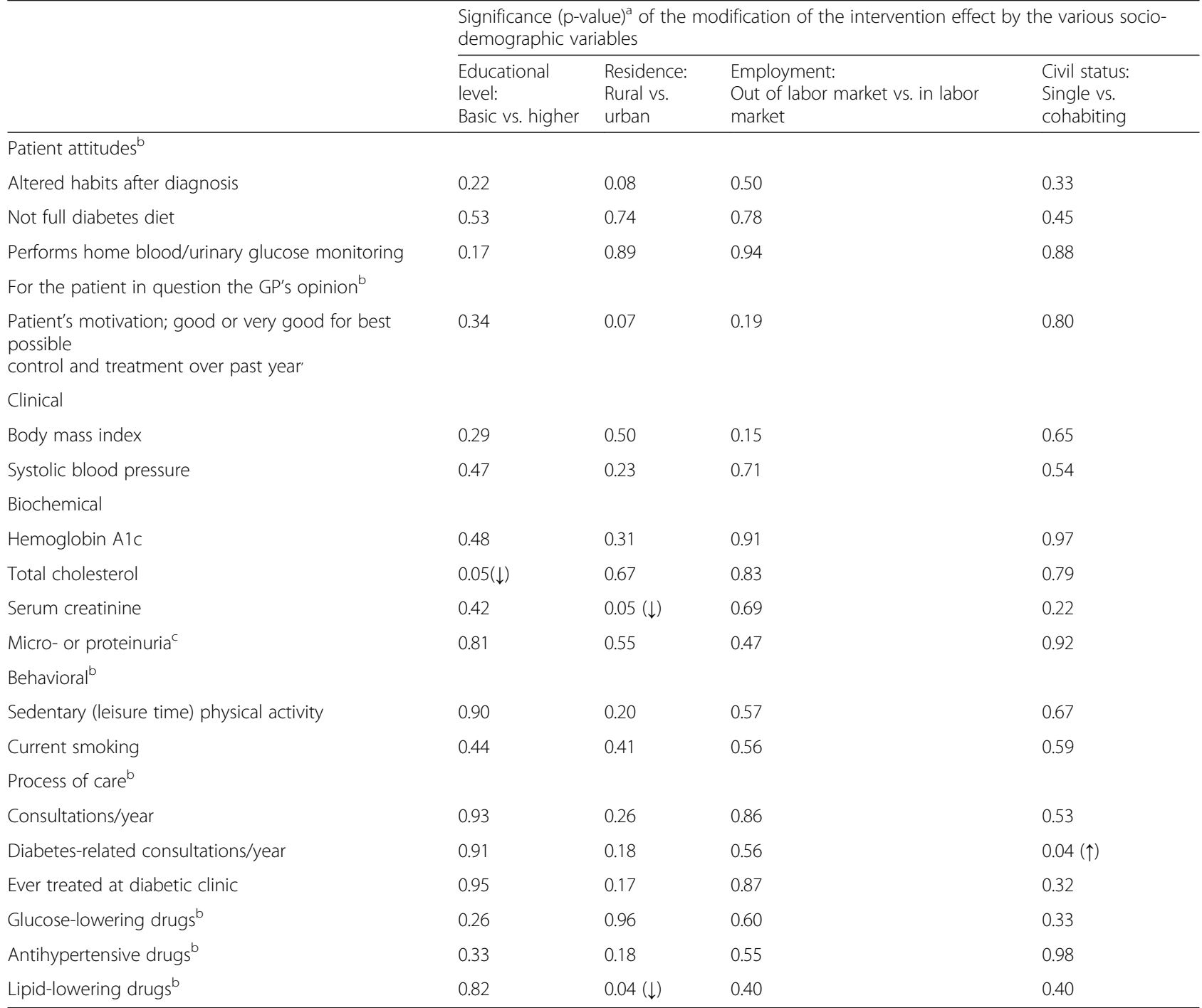

${ }^{\mathrm{a}}$-value from a test whether the effect of the intervention differs between socio-demographic groups (e.g. patients with basic school only vs higher education), adjusted for age, sex and diabetes duration. Clustering with general practice is accounted for by the use of generalized estimating equations. Arrows ( $\downarrow$ ) indicate the direction of the effect modification for cases where $p<0.05$, e.g. the intervention lowered serum creatinine more in patients living in rural areas than in patients living in urban areas. ${ }^{b}$ Data from questionnaires to patients and their general practitioners. ${ }^{\mathrm{c}}$ Proteinuria $>=15 \mathrm{mg} / \mathrm{L}$

The presented benefit of structured personal care on long-term endpoints, also for patients with low level of education and patients on welfare benefits, cannot be ascribed to single elements of complex interventions. Patients with low level of education and income are frequently reported to be inadequately controlled with hyperglycaemia, hypertension, dyslipidaemia and unhealthy lifestyle $[14,15]$, and some studies also suggest socio-demographic differences in prescription rates [16, 20]. Our results are in line with earlier studies, concerning socio-demographic differences of intensive multifactorial interventions, which have been shown not to worsen or introduce social inequity in the control of T2DM [13, 21, 33]. Prior studies suggest that interventions seem to be effective, also among patient with low SES, in improving cardiovascular risk factors and prescription of medicine, but it is more difficult to assist patients in changing lifestyle and attitudes towards DM [13, $21,33,34]$. As a high-risk group patients with low SES have potentially more to win $[9,10]$, but they are also known to have poor compliance especially regarding lifestyle and attitudes towards DM $[5,14,15]$. The individualization of diabetes care in the DCGP trial with negotiation of treatment goals, taking patient resources in consideration may explain why this intervention seems to be effective across the spectrum of SES.

Our results indicate that patients living in rural areas may have less benefit of the intervention compared to urban patients. An explanation for this finding could be 
because the uptake of the intervention was lower among rural doctors and/or because the compliance with the intervention among rural patients was low. We could not see any systematic differences in the 6 year follow up, on cardiovascular risk factors or behaviour between urban and rural patients that could reconcile these finding (Table 3). However, our data suggest that rural patients are less often treated with cholesterol-lowering drugs as a result of the intervention, but few patients were actually treated with this medication in the middle of the 1990s. Other studies have reported that cholesterol-lowering agents are less often prescribed in deprived areas [34]. A previous Scandinavian study reported no difference in mortality between urban and rural patients [8], like our study, other studies have suggested that people residing in more rural areas more often have undiagnosed diabetes $[35,36]$. This implies that rural patients may be diagnosed at a later stage of the disease, possibly with a higher risk of complications and maybe less susceptible to treatment interventions than patients living in urban areas, this have to be investigated further.

\section{Strengths and weaknesses of the study}

This study contributes to the knowledge on how SES and urbanisation influence the uptake and effect of diabetes interventions and may offer some advantages in comparison to prior studies. It is a strength of the present study that it reports hard endpoints after 19 years of follow up, but on the other hand a limitation that the results are from an early cohort.

Furthermore, the results are likely to be generalizable to the wider population of patients with T2DM because the study was population-based, with no upper age limit, but also because the study was conducted in general practice where most T2DM patients are treated. Also, the elements of the intervention, including the negotiation of treatment goals between patient and doctor, resemble standard treatment procedures in current day general practice diabetes care and recommendations [25, 26]. Finally, the study had a relative high number of GPs participating and the patient attrition rate was low.

The most important limitation of this study is that it is a post hoc analysis of a randomized controlled trial. Since randomization did not take socio-demography into account, this could have created imbalance between the randomization groups in relation to socio-demography, this does not seem to be the case. We although found a minor difference in randomization regarding residence that means one should be cautious when interpreting these results. The fact that we could not describe any substantial difference between rural and urban patients at the 6 years clinical follow up - means that the described potential difference in effect has to be investigated further. It is also a limitation that some elements of the intervention in the structured care arm were later applied to the routine care arm through national diabetes guidelines. The intervention could therefore prove to be more efficient than reported.

Information on educational level, employment and civil status were self-reported which might cause misclassification, but on the other hand, this information is readily at hand for the physician. Furthermore, some of the reported socio-demographic differences in mortality and morbidity could be due to patients with low level of education, outside the labour market or living alone being diagnosed later in the natural history of diabetes $[9,37]$ and therefore presenting with a more advanced disease at diagnosis [13]. Also a higher prevalence of comorbidity among patients with low SES in general could influence the result. We could however only find moderate decline in the association between low socioeconomic status and any diabetes-related endpoint when adjusting for comorbidity and baseline cardiovascular risk factors, which is in accordance with other studies $[1,11]$. Long-term outcomes were registry-based and vital status was confirmed for all study participants. Not all non-fatal outcomes have been tested for validity, but this is generally considered to be acceptable $[29,30]$, and differential misclassification according to treatment allocation and socio-demography is not expected.

\section{Conclusion}

Structured personal diabetes care showed effect on the aggregate outcome any diabetes-related endpoint, even for the high-risk group of patients with low level of education and patients out of the labour market. Thus, structured personal care did not give rise to more health inequality among patients with diabetes but rather a tendency in the opposite direction. Patients living in rural areas, however, seemed to have gained less from the intervention compared to patients living in urban areas this finding has to be investigated further. Still, socioeconomic inequity in mortality and morbidity existed despite the intervention.

\section{Additional files}

Additional file 1: Definition of clinical outcomes in the 19-year registrybased monitoring of the DCGP study, any diabetes related endpoint (list). (DOCX $76 \mathrm{~kb}$ )

Additional file 2: Table S1. The effect of structured personal care on behavioral, clinical, process of care and biochemical variables according to level of education (DOCX $35 \mathrm{~kb}$ )

Additional file 3: Table S2. The effect of structured personal care on behavioral, clinical, process of care and biochemical variables according to civil status (DOCX $37 \mathrm{~kb}$ )

Additional file 4: Table S3. The effect of structured personal care on behavioral, clinical, process of care and biochemical variables according 
to employment status (out of labor market vs. in labor market, retired excluded) (DOCX $37 \mathrm{~kb})$

Additional file 5: Table S4. The effect of structured personal care on behavioral, clinical, process of care and biochemical variables according to residence (Rural vs. Urban) (DOCX 37 kb)

\section{Abbreviations}

BMI: Body Mass Index; Cl: Confidence interval; DCD: Danish register of Causes of Death; DCGP: Diabetes in General Practice; DM: Diabetes mellitus; DNPR: Danish National Patient Register; GP: General Practitioner; HbA1c: Haemoglobin A1c; HR: Hazard Ratio; SES: Socio-economic status; T2DM: Type 2 Diabetes Mellitus

\section{Acknowledgements}

Gratitude to all the participants and GP's of the DCGP-trial.

\section{Funding}

This project was supported by: Region Zealand Research Fund, Copenhagen University Faculty of health sciences and University of Copenhagen 2016 Excellence program to LIFESTAT.

\section{Availability of data and materials}

The datasets used and/or analysed during the current study are available from the corresponding author on reasonable request.

\section{Authors contributions}

$\mathrm{AH}$ developed the research question and wrote the protocol for this follow-up study together with the other authors. NdFO was responsible for the original study design, randomisation, intervention delivery and data collection. VS performed the statistical analyses. All authors made substantial contributions to the analysis and interpretation of data. $\mathrm{HBH}$ contributed with social theory. The paper was written by $\mathrm{AH}, \mathrm{NdFO}$ and VS and the other authors revised it critically for important intellectual content. All authors, external and internal, had full access to all of the data (including statistical reports and tables) in the study and take responsibility for the integrity of the data and the accuracy of the data analysis. All authors have approved the final version of the manuscript.

\section{Ethics approval and consent to participate}

All patients gave verbal informed consent to participate, following a dialogue with their GP, where the patients could ask questions, to secure an informed consent. The Ethics Committee of Copenhagen and Frederiksberg (V.100.869/87) approved the study and this procedure for informed consent. When the study started off in 1988 it was coutume to seek informed consent orally.

\section{Consent for publication}

Not applicable.

\section{Competing interests}

The authors declare that they have no competing interests

\section{Publisher's Note}

Springer Nature remains neutral with regard to jurisdictional claims in published maps and institutional affiliations.

\footnotetext{
Author details

${ }^{1}$ Section of General Practice, Institute of Public Health, Faculty of Health Sciences, University of Copenhagen, Øster Farimagsgade 5, Copenhagen, Denmark. ${ }^{2}$ The Research Unit for General Practice, Department of Public Health, University of Copenhagen, Copenhagen, Denmark. ${ }^{3}$ Department of Production, Research, and Innovation, Sorø, Region Zealand, Denmark. ${ }^{4}$ Department of Laboratory Medicine, Boston Children's Hospital Study, Boston, MA, USA. ${ }^{5}$ Department of Clinical Medicine, Faculty of Health and Medical Sciences, University of Copenhagen, Copenhagen, Denmark. ${ }^{6}$ Department of Social Medicine, University of Copenhagen, Copenhagen, Denmark.
}

Received: 25 July 2017 Accepted: 29 November 2017 Published online: 08 December 2017

\section{References}

1. Walker J, Halbesma N, Lone N, McAllister D, Weir CJ, Wild SH. Scottish diabetes research network epidemiology G: socioeconomic status, comorbidity and mortality in patients with type 2 diabetes mellitus in Scotland 2004-2011: a cohort study. J Epidemiol Community Health. 2016, Jun;70(6):596-601.

2. Poulsen $K$, Cleal B, Willaing I. Diabetes and work: 12-year national follow-up study of the association of diabetes incidence with socioeconomic group age, gender and country of origin. Scandinavian journal of public health. 2014:42(8):728-33.

3. Dagenais GR, Gerstein HC, Zhang X, McQueen M, Lear S, Lopez-Jaramillo P, Mohan V, Mony P, Gupta R, Kutty VR, et al. Variations in diabetes prevalence in low-, middle-, and high-income countries: results from the prospective urban and rural epidemiological study. Diabetes Care. 2016;39(5):780-7.

4. Green A, Sortso C, Jensen PB, Emneus M. Incidence, morbidity, mortality, and prevalence of diabetes in Denmark, 2000-2011: results from the diabetes impact study 2013. Clinical epidemiology. 2015;7:421-30.

5. Wilf-Miron R, Peled R, Yaari E, Shem-Tov O, Weinner VA, Porath A, Kokia E. Disparities in diabetes care: role of the patient's socio-demographic characteristics. BMC Public Health. 2010;10:729.

6. Booth GL, Bishara P, Lipscombe LL, Shah BR, Feig DS, Bhattacharyya O, Bierman AS. Universal drug coverage and socioeconomic disparities in major diabetes outcomes. Diabetes Care. 2012;35(11):2257-64.

7. Bachmann MO, Eachus J, Hopper CD, Davey Smith G, Propper C, Pearson NJ, Williams S, Tallon D, Frankel S. Socio-economic inequalities in diabetes complications, control, attitudes and health service use: a cross-sectional study. Diabetic medicine : a journal of the British Diabetic Association. 2003; 20(11):921-9.

8. Forssas E, Manderbacka K, Arffman M, Keskimaki I. Socio-economic predictors of mortality among diabetic people. Eur J Pub Health. 2012; 22(3):305-10

9. Dray-Spira R, Gary-Webb TL, Brancati FL. Educational disparities in mortality among adults with diabetes in the U.S. Diabetes Care. 2010;33(6):1200-5.

10. Sortso C, Lauridsen J, Emneus M, Green A, Jensen PB. Social inequality in diabetes patients' morbidity patterns from diagnosis to death - a Danish register-based investigation. Scandinavian journal of public health. 2017: 1403494817713648

11. Saydah SH, Imperatore G, Beckles GL. Socioeconomic status and mortality: contribution of health care access and psychological distress among U.S. adults with diagnosed diabetes. Diabetes Care. 2013;36(1):49-55.

12. Sundquist $K$, Chaikiat A, Leon VR, Johansson SE, Sundquist J. Country of birth, socioeconomic factors, and risk factor control in patients with type 2 diabetes: a Swedish study from 25 primary health-care centres. Diabetes Metab Res Rev. 2011;27(3):244-54.

13. Baz L, Muller N, Beluchin E, Kloos C, Lehmann T, Wolf G, Muller UA. Differences in the quality of diabetes care caused by social inequalities disappear after treatment and education in a tertiary care centre. Diabetic medicine: a journal of the British Diabetic Association. 2012;29(5):640-5.

14. Rabi DM, Edwards AL, Svenson LW, Sargious PM, Norton P, Larsen ET, Ghali WA. Clinical and medication profiles stratified by household income in patients referred for diabetes care. Cardiovasc Diabetol. 2007;6:11.

15. Heltberg A, Andersen JS, Kragstrup J, Siersma V, Sandholdt H, Ellervik C. Social disparities in diabetes care: a general population study in Denmark. Scand J Prim Health Care. 2017;35(1):54-63.

16. Ward PR, Noyce PR, St Leger AS. How equitable are GP practice prescribing rates for statins?: an ecological study in four primary care trusts in north West England. Int J Equity Health. 2007;6:2.

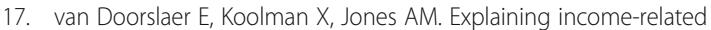
inequalities in doctor utilisation in Europe. Health Econ. 2004;13(7):629-47.

18. Hansen LJ, Siersma V, Beck-Nielsen H, de Fine Olivarius N. Structured personal care of type 2 diabetes: a 19 year follow-up of the study diabetes Care in General Practice (DCGP). Diabetologia. 2013;56(6):1243-53.

19. Pedersen $O$, Gaede P. Intensified multifactorial intervention and cardiovascular outcome in type 2 diabetes: the Steno-2 study. Metab Clin Exp. 2003;52(8 Suppl 1):19-23.

20. Sortso C, Lauridsen J, Emneus M, Green A, Jensen PB. Socioeconomic inequality of diabetes patients' health care utilization in Denmark. Heal Econ Rev. 2017;7(1):21. 
21. Dalsgaard EM, Vestergaard M, Skriver MV, Borch-Johnsen K, Lauritzen T, Sandbaek A. Socioeconomic position and cardiovascular risk factors among people with screen-detected type 2 DM: six-year follow-up of the ADDITION-Denmark trial. Primary care diabetes. 2014:8(4):322-9.

22. Krag MO, Hasselbalch L, Siersma V, Nielsen AB, Reventlow S, Malterud K, de Fine Olivarius $\mathrm{N}$. The impact of gender on the long-term morbidity and mortality of patients with type 2 diabetes receiving structured personal care: a 13 year follow-up study. Diabetologia. 2015;

23. Larsen JR, Siersma VD, Davidsen AS, Waldorff FB, Reventlow S, de Fine Olivarius N. The excess mortality of patients with diabetes and concurrent psychiatric illness is markedly reduced by structured personal diabetes care: a 19-year follow up of the randomized controlled study diabetes Care in General Practice (DCGP). Gen Hosp Psychiatry. 2016;38:42-52.

24. Olivarius NF, Beck-Nielsen $H$, Andreasen AH, Horder M, Pedersen PA. Randomised controlled trial of structured personal care of type 2 diabetes mellitus. BMJ. 2001;323(7319):970-5.

25. NICE NIfHaCE: Type 2 diabetes in adults: management. 2015 updated 2017, https://www.nice.org.uk/guidance/ng28, Accesed 1 Nov 2017.

26. Danish Society of General Practice D: Clinical recomendation for GP. Type 2diabetes - et metabolisk syndrom 2012 [Type 2-diabetes - a metobolic syndrome 2012]: http://vejledninger.dsam.dk/type2/ (accessed 12 Aug 2017).

27. Statistik D (ed.): Statistisk årbog 1997 "Statistical Yearbook 1997", 101 edn: Danmarks Statistik; 1997.

28. Pedersen CB. The Danish civil registration system. Scandinavian journal of public health. 2011;39(7 Suppl):22-5.

29. Helweg-Larsen K. The Danish register of causes of death. Scandinavian journal of public health. 2011;39(7 Suppl):26-9.

30. Lynge E, Sandegaard JL, Rebolj M. The Danish National Patient Register. Scandinavian journal of public health. 2011;39(7 Suppl):30-3.

31. Holman RR, Paul SK, Bethel MA, Matthews DR, Neil HA. 10-year follow-up of intensive glucose control in type 2 diabetes. N Engl J Med. 2008;359(15):1577-89.

32. Dalsgaard EM, Vedsted $P$, Fenger-Gron M, Sandbaek A, Vestergaard $M$. Socioeconomic position and contact to general practice among persons with diabetes. Primary care diabetes. 2012;6(4):313-8.

33. O'Kane MJ, McMenamin M, Bunting BP, Moore A, Coates VE. The relationship between socioeconomic deprivation and metabolic/ cardiovascular risk factors in a cohort of patients with type 2 diabetes mellitus. Primary care diabetes. 2010;4(4):241-9.

34. Wild S, Macleod F, McKnight J, Watt G, Mackenzie C, Ford I, McConnachie A, Lindsay RS. Impact of deprivation on cardiovascular risk factors in people with diabetes: an observational study. Diabetic medicine : a journal of the British Diabetic Association. 2008;25(2):194-9.

35. Bergholdt HK, Bathum L, Kvetny J, Rasmussen DB, Moldow B, Hoeg T, Jemec GB, Berner-Nielsen H, Nordestgaard BG, Ellervik C. Study design, participation and characteristics of the Danish general suburban population study. Danish medical journal. 2013;60(9):A4693.

36. Leahy S, OH AM, OL N, Healy M, McCormack M, Kenny RA, OC J. Prevalence and correlates of diagnosed and undiagnosed type 2 diabetes mellitus and pre-diabetes in older adults: findings from the Irish longitudinal study on ageing (TILDA). Diabetes Res Clin Pract. 2015;1 10(3):241-9.

37. Heltberg A, Andersen JS, Sandholdt H, Siersma V, Kragstrup J, Ellervik C. Predictors of undiagnosed prevalent type 2 diabetes - the Danish general suburban population study. Primary care diabetes. 2017;

\section{Submit your next manuscript to BioMed Central and we will help you at every step:}

- We accept pre-submission inquiries

- Our selector tool helps you to find the most relevant journal

- We provide round the clock customer support

- Convenient online submission

- Thorough peer review

- Inclusion in PubMed and all major indexing services

- Maximum visibility for your research

Submit your manuscript at www.biomedcentral.com/submit

) Biomed Central 